\title{
OPTIMIZATION OF THE INTELLIGENT WORKSHOP CONTROL BASED ON THE IMPROVED GROUP LEADERSHIP OPTIMIZATION ALGORITHM
}

\author{
Xue, P. ; Jiang, C. H. ${ }^{* *}$; Wei, W. ${ }^{* *} \&$ Lin, J., ${ }^{* * *, \#}$ \\ * College of Instrumentation and Electrical Engineering, Jilin University, Changchun 130061, China \\ ***Eectrical and Electronic Engineering, Changchun University of Technology, Changchun 130012, \\ China \\ Key Laboratory of Geo-Exploration and Instrumentation of Education Ministry, Jilin University, \\ Changchun 130061, China \\ E-Mail: lin_jun@jlu.edu.cn ( ${ }^{\#}$ Corresponding author)
}

\begin{abstract}
This paper takes the existing optimized single product production scheduling scheme as the cloud service resource, and the production planning scheme for the product to be processed as the request task, and then subjects the two to semantic search and matching to generate a set of optimal production planning schemes. Then this paper innovatively takes the minimum production and processing cost, processing time, equipment state and minimum transport distance in product processing as the objective functions, and uses the penalty function to establish the fitness function to constrain the group leader optimization algorithm. After that, the proposed improved group leader optimization algorithm (GLOA) is used to screen the generated scheme set, and finally the optimal intelligent workshop control and scheduling scheme is obtained. The simulation results show that the proposed GLOA algorithm achieves a good convergence and is well adaptable. The research conclusions can provide theoretical reference for the intelligent workshop control and scheduling in single product manufacturing.

(Received, processed and accepted by the Chinese Representative Office.)
\end{abstract}

Key Words: Intelligent Workshop, Optimization of Scheduling Control, Group Leadership Optimization Algorithm, Penalty Function

\section{INTRODUCTION}

With the increasing demand for specialized, personalized and diversified products in the production market, production of single-piece custom-made products has gradually become the main production mode for many manufacturers [1]. Custom-made products, such as deep mining equipment, special processing machines, vessels under harsh conditions and custommade cars, etc., differ a lot from common products in terms of appearance, size and function [2]. Due to the complex production process, the difficult scheduling and the infeasibility for mass production, the conventional workshop production scheduling mode is not applicable to the manufacturing of single-piece products. Therefore, it has become a research hotspot to explore new optimized intelligent production scheduling modes to realize intelligent manufacturing [3-5].

At present, most manufacturing companies resort to intelligent methods (cloud manufacturing, cloud service, Internet of Things, etc.) to optimize the production and processing scheduling of single-piece customized products and obtain real-time information on production scheduling and logistics through the cloud manufacturing platform [6-11]. Production and processing planning, as the core of production scheduling, is the foundation for the optimal processing and rational resource allocation of single-piece products. So far, researchers have carried out extensive research on the intelligent production and processing planning and rational resources allocation [12-15]. For example, Framinan and Perez- 
Gonzalez used the greedy search algorithms to solve the optimal scheduling of multiple personalized orders [16]; Gomes et al. optimized the single-piece customized production scheduling based on the proposed predictive-reactive scheduling algorithm [17]; Yang et al. proposed a genetic algorithm with priority rules that takes into account factors such as scrap rate, temporary increase of product and delivery rate during production and processing [18]; aiming to reduce search space and computing time, Vidal et al. proposed an algorithm combining evolutionary computation and BP neural network to solve the scheduling efficiency reduction caused by product diversity [19]. Phanden et al. and Li et al. also studied the optimal scheduling of production and processing by intelligent means from different angles [20, 21].

The above research results can achieve good scheduling effect when the product processing scale is small, but when the scale is larger, they will be no longer applicable to the intelligent process planning and decision making of the workshop production [22-24]. In recent years, some researchers have worked on sharing the information, equipment and resources of different manufacturing enterprises through the service platform such as cloud manufacturing to realize the individualized needs of customers, so as to achieve the reutilization of processing resources and previous experience $[25,26]$.

By referring to the processing decision-making method of "cloud service manufacturing", this paper takes the existing optimized single product production scheduling scheme as the cloud service resource, and the production planning scheme for the products to be processed as the request task, and then subjects the two to semantic search and matching to generate a set of optimal production planning schemes. It then uses the proposed improved group leader optimization algorithm (GLOA) to screen the generated scheme set, and finally obtains the optimal intelligent workshop control and scheduling scheme.

\section{RELATED CONCEPTS AND PROBLEM DESCRIPTION}

This section first explains some concepts mentioned in this paper.

Processing features of product parts: these are the basis for intelligent workshop control and scheduling optimization. They contain all the dimensional information and processing requirements of the product parts. The parts of the one-piece product include $n$ general machining features $F_{i}$ :

$$
F_{i}=\left\{F_{1}, F_{2}, F_{3}, . . F_{i}, \ldots, F_{n}\right\}
$$

$F_{i}$ generally refers to the shapes, grooves and chamfers, etc. of the parts, and is generally achieved by the combination of various processing schemes.

Semantic matching: this paper uses the ontology web language (OWL) to describe the related services of workshop production and processing scheduling, mainly including the input, output, premise and effect of cloud services. OWL can make the customer's needs better understood by the manufacturer.

Real-time status of processing equipment: the status (S) of all processing equipment in the workshop is collected by a radio frequency identification device in real time, and can be evaluated with the following equations:

- Processing equipment load rate $d_{1}$

$$
d_{1}=T_{\mathrm{e}} /\left(T_{\mathrm{w}}+T_{\mathrm{r}}\right) \times 100 \%
$$

- Equipment processing pass rate $d_{2}$

$$
d_{2}=n_{\mathrm{g}} / n \times 100 \%
$$

- Product processing completion rate $d_{3}$ 


$$
d_{3}=n / n_{\mathrm{p}} \times 100 \%
$$

- Equipment failure rate $d_{4}$

$$
d_{4}=T_{\mathrm{s}} / T_{\mathrm{w}} \times 100 \%
$$

$T_{\mathrm{e}}, T_{\mathrm{w}}$, and $T_{\mathrm{r}}$ represent the actual working time, theoretical working time, and breakdown maintenance time of the equipment; $n$ is the number of products; $n_{\mathrm{p}}$ is the number of products to be processed.

Fig. 1 shows the intelligent workshop processing scheduling and decision-making process designed in this paper.

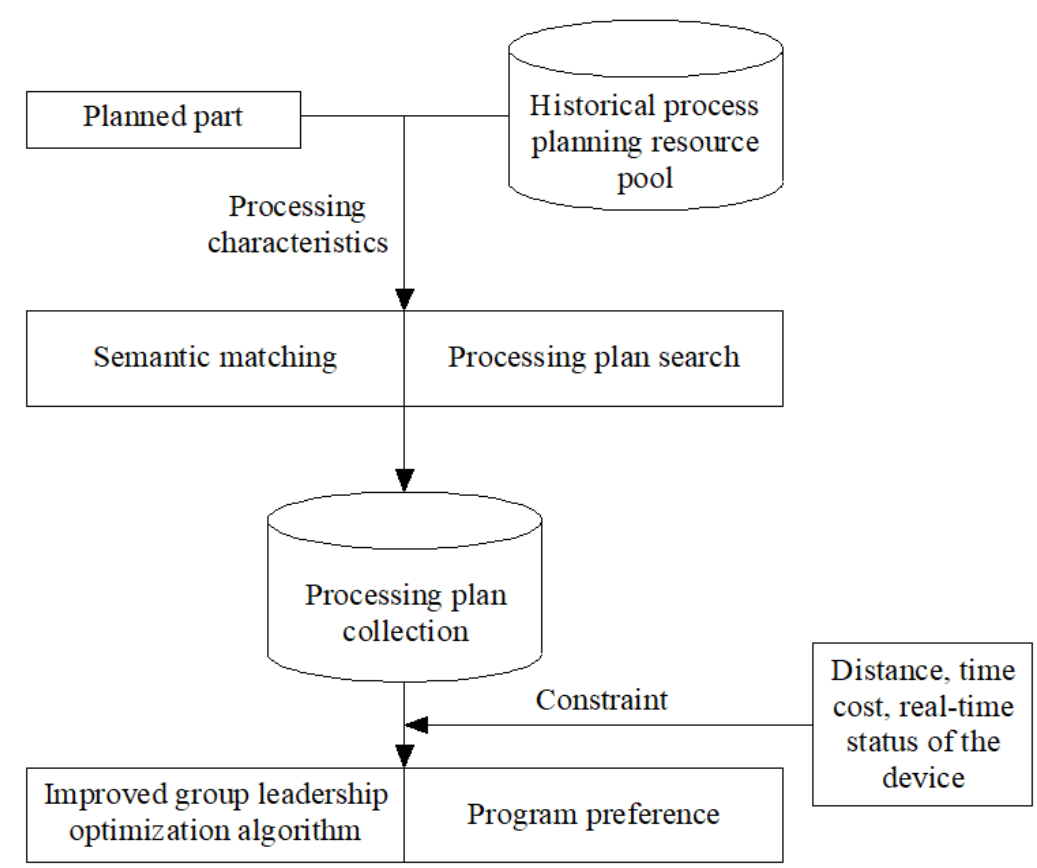

Figure 1: Intelligent workshop product processing scheduling and decision-making process.

In the product processing planning, the first step is to conduct semantic matching of schemes, so that the optimal processing scheduling scheme can be selected from the set of historical schemes and design schemes. The matching rule is based on the concepts of parameters within the scheme.

$$
\operatorname{sim}\left(L_{1}, L_{2}\right)=\left\{\begin{array}{cl}
1, & L_{1}=L_{2} \\
\frac{1}{1+\operatorname{dis}\left(L_{1}, L_{2}\right)}, & \text { Inheritance relationship } \\
0, & \text { No inheritance relationship }
\end{array}\right.
$$

$L_{1}$ and $L_{2}$ are arbitrary sub-concepts in the set of scheme concepts, and $\operatorname{dis}\left(L_{1}, L_{2}\right)$ is the distance between the two, and there are

$$
\operatorname{dis}\left(L_{1}, L_{2}\right)=\left\{\begin{array}{cc}
0, & L_{1}=L_{2} \\
l_{\left(L_{1}, L_{2}\right)} \times \sum \omega(n), & \text { Inheritance relationship } \\
\infty, & \text { No inheritance relationship }
\end{array}\right.
$$

The matching degree of the statement concepts is verified according to Eq. (6). When there is a mismatch, the original production and processing plan will be adjusted, and the above mismatch will be included in the historical planning schemes. The semantic matching process of intelligent workshop scheduling is shown in Fig. 2. 


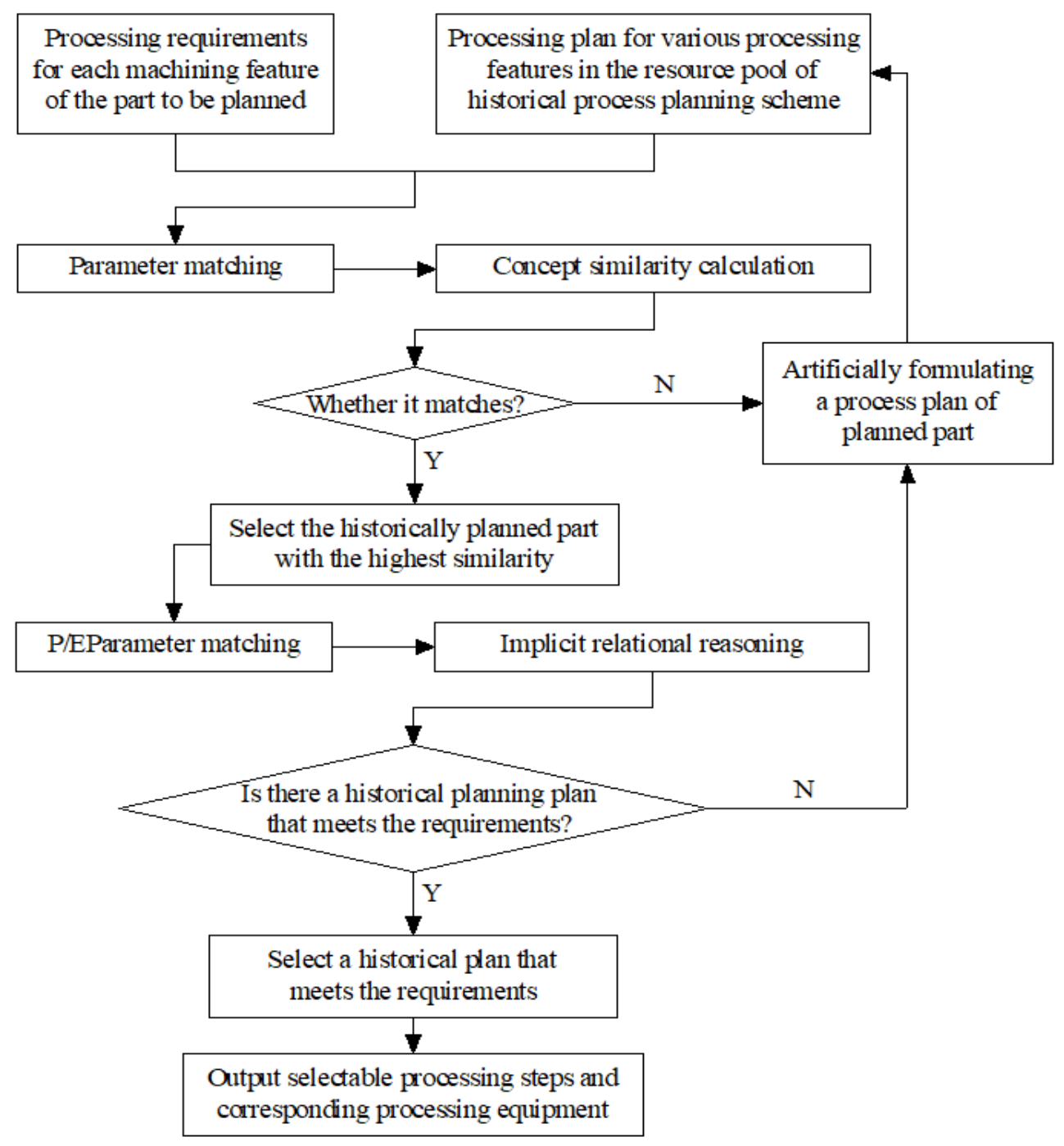

Figure 2: Semantic matching process of intelligent workshop scheduling.

After intelligent matching, the candidate scheme set is formed as follows:

$$
V^{i}=\left\{V_{1_{i}}^{i}, V_{2_{i}}^{i}, V_{3_{i}}^{i}, \ldots, V_{k_{i}}^{i}, \ldots, V_{\mu_{i}}^{i}\right\} \quad i=1,2, \ldots, n
$$

where, $V^{i}$ represents the candidate optimization scheme, in which, the specific relationship between the process and the equipment is shown in Fig. 3 .

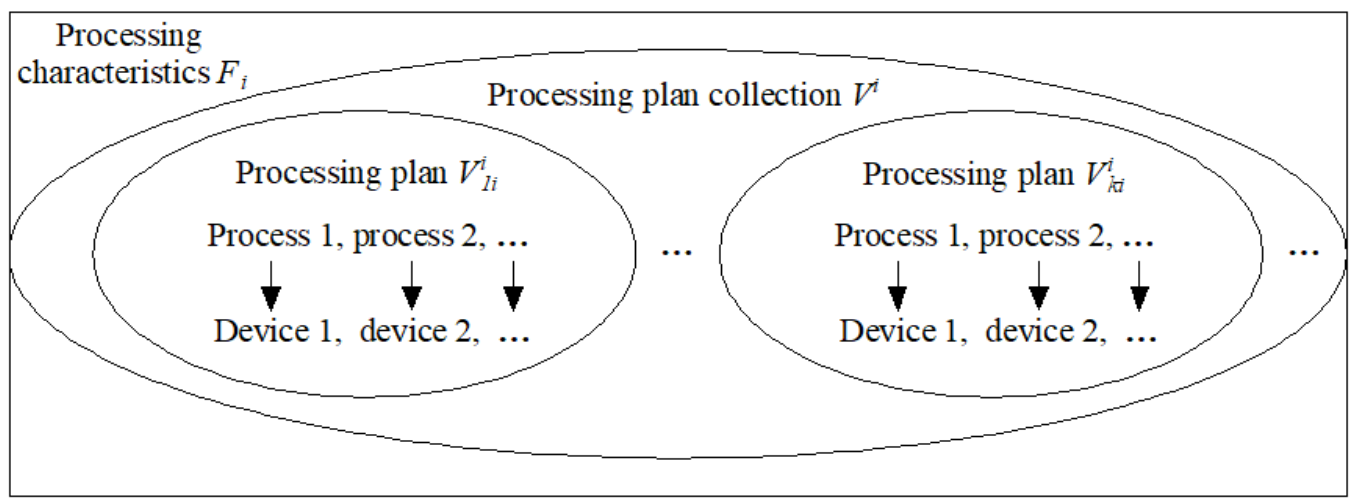

Figure 3: Relationships between processes, processing features and equipment in a candidate intelligent processing scheme. 


\section{INTELLIGENT WORKSHOP SCHEDULING SCHEME MODEL AND SOLUTION METHOD}

\subsection{Mathematic model for the scheduling scheme}

This paper takes the minimum production and processing cost, processing time, equipment state and minimum transport distance in product processing as the optimization objectives, and establishes the mathematical model for the intelligent workshop scheduling scheme $[27,28]$. The objective function is as follows:

- Minimum transport distance $D$ in product processing:

$$
D=\min \sum_{i=1}^{n} \sum_{k=1}^{\mu} D_{V_{k_{i}}^{i}} \alpha_{k}^{i}
$$

- Shortest overall processing time $T$ :

$$
T=\min \sum_{i=1}^{n} \sum_{k=1}^{\mu} \sum_{j=1}^{m} D_{V_{k_{i}}^{i}}^{j} \alpha_{k}^{i}
$$

- Minimum overall processing cost $C$ :

$$
C=\min \sum_{i=1}^{n} \sum_{k=1}^{\mu} \sum_{j=1}^{m} C_{V_{k_{i}}^{i}}^{j} \alpha_{k}^{i}
$$

- Optimal equipment processing state $S$ :

$$
S=\frac{1}{m} \max \sum_{i=1}^{n} \sum_{k=1}^{\mu} \sum_{j=1}^{m} S_{V_{k_{i}}^{i}}^{j} \alpha_{k}^{i}
$$

The mathematical optimization model established in this paper targets the multi-objective minimum value of Eqs. (9) to (12).

$$
\begin{aligned}
& f=\min \left(\omega_{1} \frac{D-D_{\min }}{D_{\max }-D_{\min }}+\omega_{2} \frac{T-T_{\min }}{T_{\max }-T_{\min }}+\omega_{3} \frac{C-C_{\min }}{C_{\text {max }}-C_{\text {min }}}+\omega_{4} S\right) \\
& \text { s.t. } \quad \sum_{q=1}^{4} \omega_{q}=1, \quad \omega_{q} \in[0,1], \quad q=1,2,3,4
\end{aligned}
$$

$\omega_{1}-\omega_{4}$ are the weighting coefficients of the four sub-objective functions. Since Eq. (12) needs to consider the range of the independent variable in the calculation process, the penalty function is used to establish the fitness function $F_{\mathrm{E}}$ :

$$
F_{\mathrm{E}}=f+M \times \sum_{k=1}^{n} h_{k}^{2}(x)
$$

$h_{k}(x)$ is the constraint equation and $M$ is the penalty coefficient.

\subsection{Model solving algorithm}

A common method for solving workshop scheduling is the heuristic intelligent algorithm. Due to the high discreteness of single-piece product processing scheduling, this paper makes an improvement to the original group leadership algorithm to solve the intelligent workshop control and scheduling model.

The group leadership optimization algorithm (GLOA) divides the searched space into subgroups, each having a leader, who is the member with the global minimum value within the sub-group. The features of a member in the group are influenced by both the leader and other members. If (after each iteration) the objective function value of the child group member is smaller than that of the parent group leader, then the leader will be automatically replaced by the above member in the next iteration. 
The relevant constrained parameters of the optimized scheduling scheme are mapped to the parameters in the GLOA algorithm one by one. In the GLOA calculation, the $p^{\text {th }}$ member in the $g^{\text {th }}$ group can be expressed with the following equations:

$$
\left\{\begin{array}{l}
x_{p}^{g}(t)=\left(x_{p, 1}^{g}(t), x_{p, 2}^{g}(t), \ldots, x_{p, j}^{g}(t), \ldots, x_{p, m}^{g}(t)\right) \\
m=\sum_{i=1}^{n} \mu_{i}
\end{array}\right.
$$

The mapping relationships between the constrained parameters of the optimized scheduling scheme and the parameters of the GLOA algorithm are shown in Fig. 4.

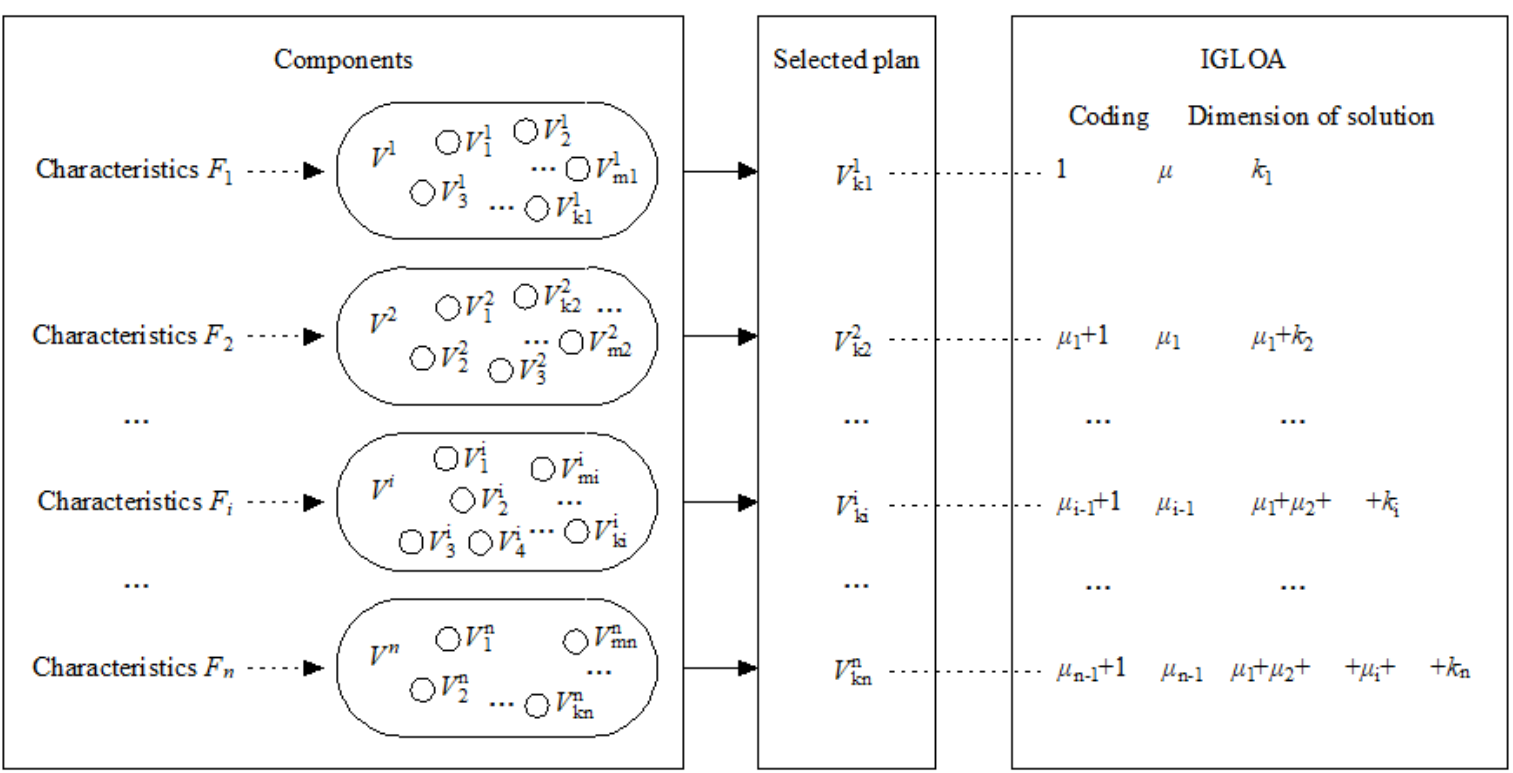

Figure 4: Mapping relationships between the constrained parameters of the optimized scheduling scheme and the parameters of the GLOA algorithm.

Fig. 5 shows the calculation process flow of the proposed GLOA.

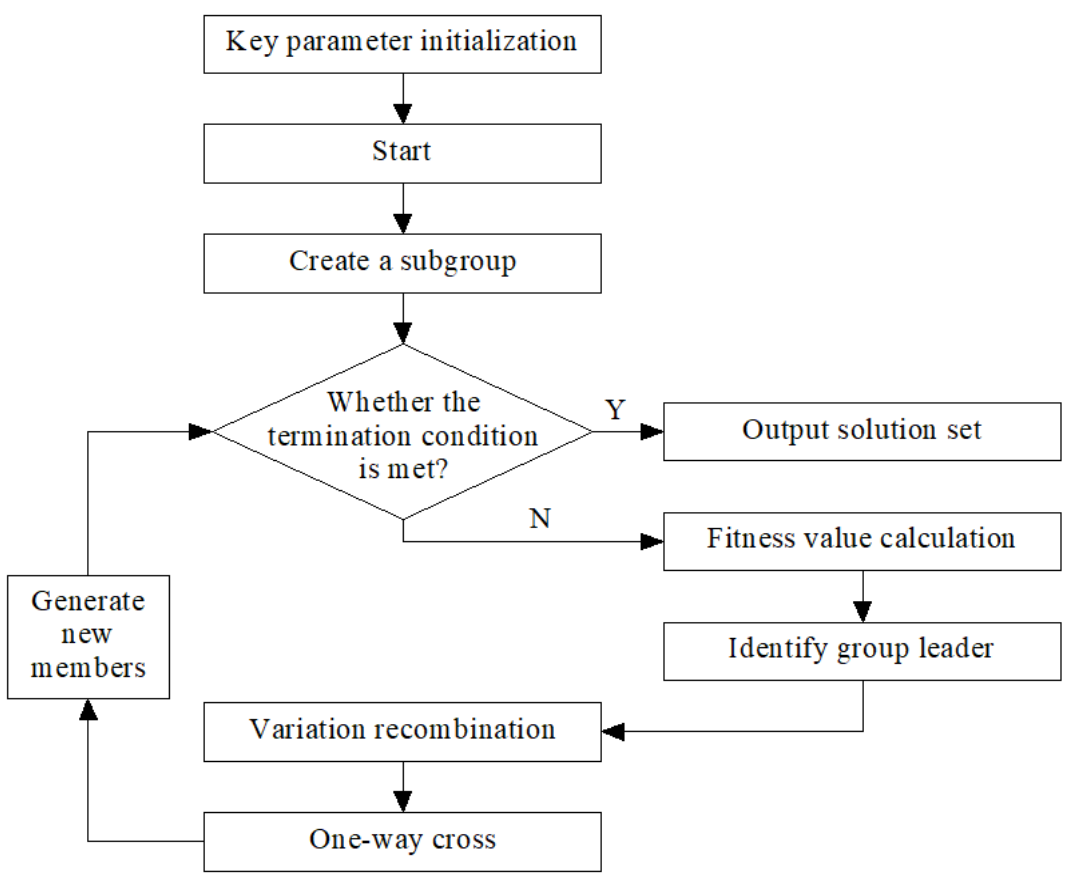

Figure 5: Calculation process flow of GLOA. 
The gth group

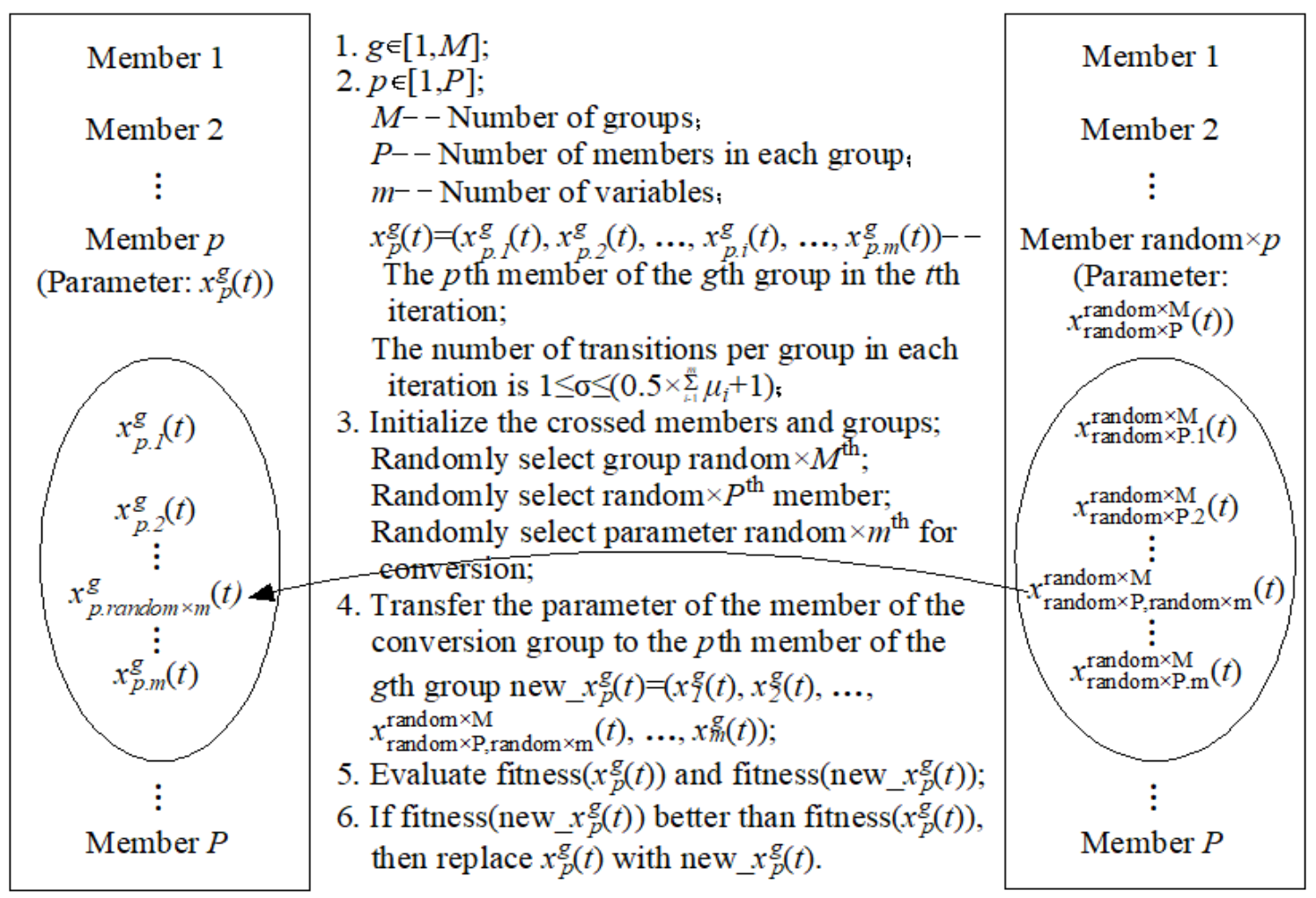

Figure 6: One-way cross calculation.

The specific steps of the algorithm are as follows:

(1) Initialization of the algorithm-related parameters. Break the initial group down into $M$ sub-groups, each having $P$ members. Calculate the fitness $F_{\mathrm{E}}$ of each member.

(2) Obtain the leader of the initial sub-group based on $F_{\mathrm{E}}$, and carry out iterative calculation $i$.

(3) Variation recombination. Conduct variation recombination of the group members so that the algorithm will finally obtain the global optimal solution. This paper uses the sequential traversing method to perform variation recombination of group members. The calculation formula is as follows:

$$
\operatorname{new}_{p}^{g}(t)=r_{1} \times x_{p}^{g}(t)+r_{2} \times \operatorname{Leader}^{g}(t)+r_{3} \times \text { Random }
$$

where, Random adopts the Gaussian distribution.

$$
\text { Random } \sim N\left(x_{p, j}^{g}, 1\right)=\frac{1}{\sqrt{2 \pi}} \exp \left[\frac{-\left(x-x_{p, j}^{g}\right)^{2}}{2}\right]
$$

(4) One-way cross calculation. The overall architecture of the one-way cross calculation is shown in Fig. 6.

(5) Select the local minimum using the method in Fig. 6. Repeat steps (2)-(4) until the optimal fitness is selected as the final solution.

\section{SIMULATION TEST AND RESULTS ANALYSIS}

This paper takes the gear shaft processing in a workshop as an example to verify the feasibility of the mathematical model and algorithm proposed. 6 processing features of the gear shaft are selected, as listed in Table I. 
Table I: Gear shaft processing features.

\begin{tabular}{|c|c|c|c|c|c|c|}
\hline $\mathbf{F}_{\mathbf{i}}$ & $\mathrm{F}_{1}$ & $\mathrm{~F}_{2}$ & $\mathrm{~F}_{3}$ & $\mathrm{~F}_{4}$ & $\mathrm{~F}_{5}$ & $\mathrm{~F}_{6}$ \\
\hline Definition & End & Cylindrical & Blind hole & Flat key & Thread & Straight tooth \\
\hline
\end{tabular}

The diameter of the cylinder is $140 \mathrm{~mm}$; the diameter of the tooth surface $130 \mathrm{~mm}$; the width of the keyway $19 \mathrm{~mm}$, the length $106 \mathrm{~mm}$, and the required machining precision IT9; and the required machining precision for other features IT7. Figs. 7 and 8 illustrate the concept tree of gear shaft machining features and the corresponding weights.

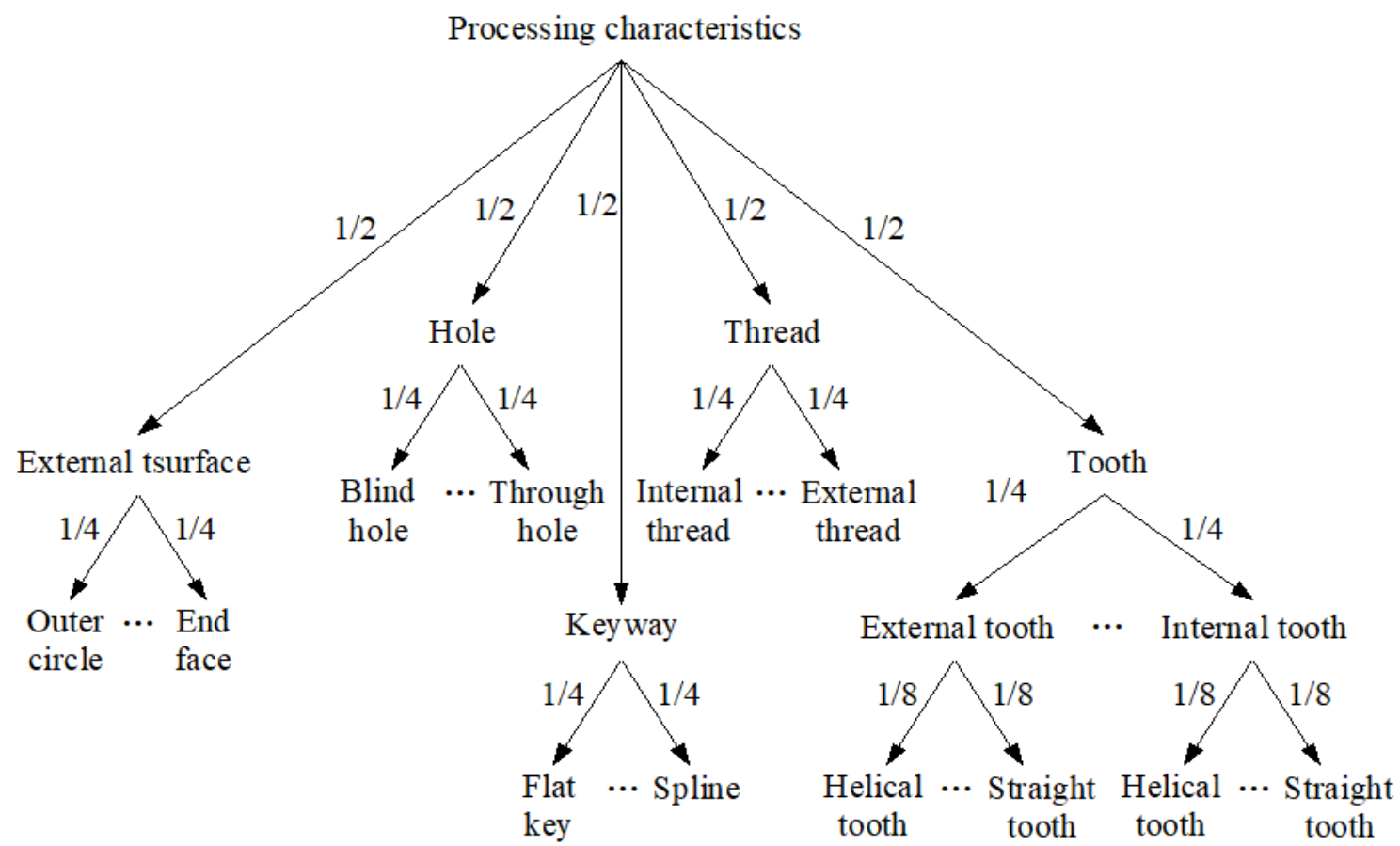

Figure 7: Concept tree of the gear shaft machining features and corresponding weights.

Processing characteristics accuracy

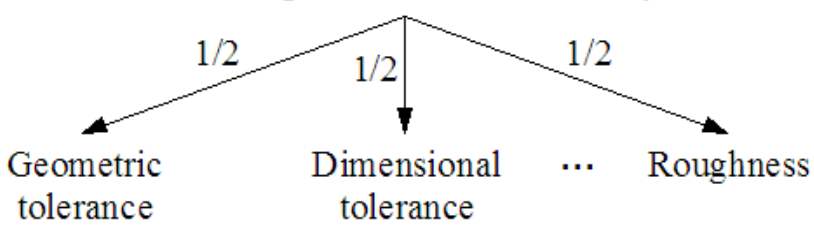

Figure 8: Concept tree of the gear shaft machining precision and corresponding weights.

According to the calculation method above, the production scheduling schemes for the cylindrical shape, the flat keyway and the straight tooth are summarized, as shown in Table II.

There are 3, 4 and 4 planned schemes for end face, blind hole and thread, respectively. According to the importance of each sub-objective function in Eqs. (9) to (12), the weights of the sub-objective functions are given as $\omega_{1}=0.17, \omega_{2}=0.26, \omega_{3}=0.28$ and $\omega_{4}=0.29$. Then according to Eq. (13), the objective function obtained is as follows: 


$$
\begin{aligned}
f & =\min \left(\omega_{1} \sum_{i=1}^{20} D_{i} x_{i}+\omega_{2} \sum_{i=1}^{20} T_{i} x_{i}+\omega_{3} \sum_{i=1}^{20} C_{i} x_{i}+\omega_{4} \sum_{i=1}^{20} S_{i} x_{i}\right) \\
\text { s.t. } & \left\{\begin{array}{l}
x_{1}+x_{2}+x_{3}=1 \\
x_{4}+x_{5}=1 \\
x_{6}+x_{7}+x_{8}+x_{9}=1 \\
x_{10}+x_{11}+x_{12}+x_{13}=1 \\
x_{14}+x_{15}+x_{16}+x_{17}=1 \\
x_{18}+x_{19}+x_{20}=1 \\
x_{1} \sim x_{20}=0 \text { or } 1
\end{array}\right.
\end{aligned}
$$

Table II: Production scheduling schemes for the cylindrical shape,

\begin{tabular}{|c|c|c|c|c|c|c|}
\hline $\begin{array}{c}\text { Processing } \\
\text { feature }\end{array}$ & $\begin{array}{l}\text { Processing } \\
\text { Scheme }\end{array}$ & Master operation & Device & $\begin{array}{c}C \\
\text { (yuan) }\end{array}$ & $\begin{array}{c}T \\
(\min )\end{array}$ & \begin{tabular}{|c|} 
\\
$(\mathrm{m})$ \\
\end{tabular} \\
\hline \multirow{2}{*}{ Cylindrical } & V2 1 & $\begin{array}{l}\text { Rough turning-semi- } \\
\text { finish turning-finish } \\
\text { turning-grinding }\end{array}$ & NC lathe, grinder & 119 & 22 & 7 \\
\hline & V2 2 & $\begin{array}{l}\text { Rough turning-semi- } \\
\text { finish turning-finish } \\
\text { turning-grinding }\end{array}$ & NC lathe, grinder & 158 & 30 & 7 \\
\hline \multirow{4}{*}{ Flat keyway } & V4 1 & $\begin{array}{l}\text { Rough milling-finish } \\
\text { milling }\end{array}$ & NC milling machine & 72 & 10 & 0 \\
\hline & V4 2 & $\begin{array}{l}\text { Rough milling-finish } \\
\text { milling }\end{array}$ & Plane miller & 92 & 7 & 0 \\
\hline & V4 3 & $\begin{array}{l}\text { Rough milling-finish } \\
\text { milling }\end{array}$ & Machining centre & 112 & 6 & 0 \\
\hline & V4 4 & $\begin{array}{c}\text { Cutting grooves-milling } \\
\text { grooves }\end{array}$ & $\begin{array}{l}\text { NC cutting machine, NC } \\
\text { milling machine }\end{array}$ & 82 & 8 & 4.5 \\
\hline \multirow{3}{*}{$\begin{array}{l}\text { Straight } \\
\text { tooth }\end{array}$} & V6 1 & $\begin{array}{l}\text { Hobbing-shaving-gear } \\
\text { honing }\end{array}$ & $\begin{array}{c}\text { Hobbing machine, shaving } \\
\text { machine, gear honing machine }\end{array}$ & 312 & 430 & 6 \\
\hline & V6 2 & $\begin{array}{c}\text { Gear shaping-shaving- } \\
\text { gear honing }\end{array}$ & $\begin{array}{l}\text { Gear shaping machine, shaving } \\
\text { machine, gear honing machine }\end{array}$ & 337 & 425 & 7 \\
\hline & V6 3 & Hobbing-gear grinding & $\begin{array}{l}\text { Hobbing machine, gear } \\
\text { grinding machine }\end{array}$ & 452 & 293 & 8 \\
\hline
\end{tabular}
the flat keyway and the straight tooth.

The traditional genetic algorithm (GA) is compared with the proposed algorithm (GLOA) here. The number of iterations is $G=200$, the initial number of groups set to 50, with 30 members in each group, and the number of groups crossed in each iteration set to 7. Fig. 9 shows the comparison of the optimal values of the GA algorithm and the GLOA algorithm.

It can be seen from Fig. 9 that the traditional GA algorithm converges very fast, and already falls into the local optimal solution in the early iteration, while the GLOA algorithm proposed in this paper converges well and reaches the global optimal solution after 99 iterations. According to the proposed mathematical model, under this algorithm, the shortest transport distance in the processing of the single-piece product is $9 \mathrm{~m}$, the minimum processing time $508 \mathrm{~min}$, the total cost $911 \mathrm{RMB}$, and the real-time status $S$ of the processing equipment 0.415 ; on the other hand, under the GA algorithm, the shortest transport distance is $9 \mathrm{~m}$, the minimum processing time $537 \mathrm{~min}$, the processing cost $878 \mathrm{RMB}$, and the $S$ value 0.601. Overall, GLOA has better fitness than GA, and the algorithm accuracy is improved by about $20 \%$, which proves the effectiveness and superiority of the proposed algorithm. 

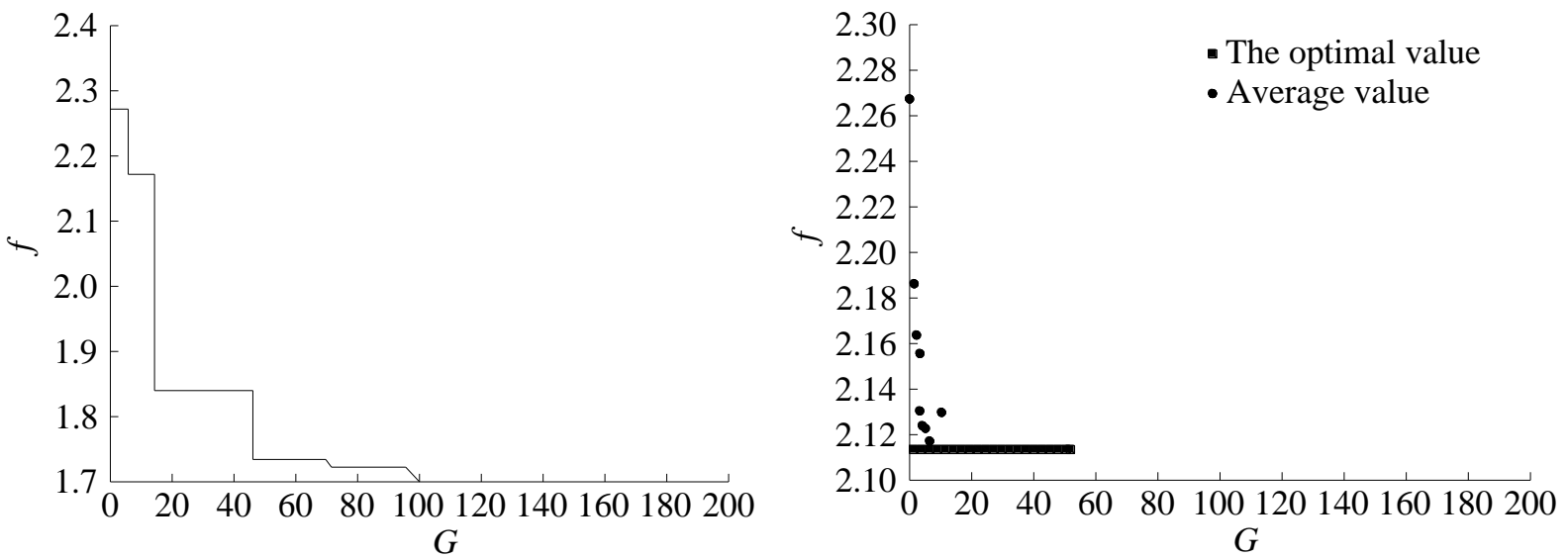

Figure 9: Comparison of the optimal values of GLOA (left) and GA (right).

\section{CONCLUSIONS}

By referring to the processing decision-making method of "cloud service manufacturing", this paper takes the existing optimized single product production scheduling scheme as the cloud service resource, and the production planning scheme for the products to be processed as the request task, and then subjects the two to semantic search and matching to generate a set of optimal production planning schemes. Then it uses the proposed improved GLOA to screen the generated scheme set, and finally obtains the optimal intelligent workshop control and scheduling scheme.

This paper innovatively takes the minimum production and processing cost, processing time, equipment state and minimum transport distance in product processing as the objective functions, and uses the penalty function to establish the fitness function to constrain the GLOA algorithm. GLOA is optimized to further adapt to the high discreteness of the single product manufacturing scheduling process.

The simulation results show that the proposed GLOA algorithm achieves a good convergence - it reaches the global optimal solution after 99 iterations, and compared with GA, GLOA has better adaptability. Both aspects prove the effectiveness and superiority of the proposed algorithm.

\section{ACKNOWLEDGEMENTS}

The study was supported by "Jilin Province science and technology development, China (Grant No. 20180201129GX)".

\section{REFERENCES}

[1] Duray, R. (2002). Mass customization origins: mass or custom manufacturing?, International Journal of Operations \& Production Management, Vol. 22, No. 3, 314-328, doi: $10.1108 / 01443570210417614$

[2] Ou, H. B.; Zhang, C. H. (2010). Scheduling intelligent optimization algorithms in manufacturing execution system, Agriculture Network Information, Vol. 25, No. 5, 112-114

[3] Li, Y. G.; Zhang, M. S. (2017). A multi-objective lot-streaming optimization scheduling model considering the blocking effect, International Journal of Simulation Modelling, Vol. 16, No. 4, 731-741, doi:10.2507/IJSIMM16(4)CO19

[4] An, Y.-W.; Yan, H.-S. (2013). Solution strategy of integrated optimization of production planning and scheduling in a flexible job-shop, Acta Automatica Sinica, Vol. 39, No. 9, 14761491, doi:10.3724/sp.j.1004.2013.01476 
Xue, Jiang, Wei, Lin: Optimization of the Intelligent Workshop Control Based on the ...

[5] Guo, Q. L.; Zhang, M. (2010). An agent-oriented approach to resolve scheduling optimization in intelligent manufacturing, Robotics and Computer-Integrated Manufacturing, Vol. 26, No. 1, 3945, doi:10.1016/j.rcim.2009.02.003

[6] Wang, X. V.; Xu, X. W. (2013). An interoperable solution for cloud manufacturing, Robotics and Computer-Integrated Manufacturing, Vol. 29, No. 4, 232-247, doi:10.1016/j.rcim.2013.01.005

[7] Li, W.; Zhong, Y.; Wang, X.; Cao, Y. (2013). Resource virtualization and service selection in cloud logistics, Journal of Network and Computer Applications, Vol. 36, No. 6, 1696-1704, doi:10.1016/j.jnca.2013.02.019

[8] Wu, L. (2011). Resource virtualization model in cloud manufacturing, Advanced Materials Research, Vol. 143-144, 1250-1253, doi:10.4028/www.scientific.net/amr.143-144.1250

[9] Fu, S. Y.; Gong, S. C.; Chen, Z. (2012). Study on the key technologies for clouding manufacturing based on virtualization technology, Advanced Materials Research, Vol. 503-504, 86-89, doi:10.4028/www.scientific.net/amr.503-504.86

[10] Li, C. Q.; Hu, C. Y.; Wang, Y. W. (2011). Research of resource virtualization technology based on cloud manufacturing, Advanced Materials Research, Vol. 201-203, 681-684, doi:10.4028/www.scientific.net/amr.201-203.681

[11] Chen, X.; Zhang, J.; Li, J.; Li, X. (2013). Resource virtualization methodology for on-demand allocation in cloud computing systems, Service Oriented Computing and Applications, Vol. 7, No. 2, 77-100, doi: $10.1007 / \mathrm{s} 11761-011-0092-9$

[12] Um, J.; Choi, Y.-C.; Stroud, I. (2014). Factory planning system considering energy-efficient process under cloud manufacturing, Procedia CIRP, Vol. 17, 553-558, doi:10.1016/ j.procir.2014.01.084

[13] Lv, S.; Qiao, L. (2014). Process planning and scheduling integration with optimal rescheduling strategies, International Journal of Computer Integrated Manufacturing, Vol. 27, No. 7, 638-655, doi: $10.1080 / 0951192 x .2013 .834468$

[14] Krishnaiyer, K.; Chen, F. F. (2017). A cloud-based Kanban decision support system for resource scheduling \& management, Procedia Manufacturing, Vol. 11, 1489-1494, doi:10.1016/ j.promfg.2017.07.280

[15] Cheng, Z.; Zhan, D.; Zhao, X.; Wan, H. (2014). Multitask oriented virtual resource integration and optimal scheduling in cloud manufacturing, Journal of Applied Mathematics, Vol. 2014, No. 7, Paper 369350, 9 pages, doi:10.1155/2014/369350

[16] Framinan, J. M.; Perez-Gonzalez, P. (2017). New approximate algorithms for the customer order scheduling problem with total completion time objective, Computers \& Operations Research, Vol. 78, 181-192, doi:10.1016/j.cor.2016.09.010

[17] Gomes, M. C.; Barbosa-Póvoa, A. P.; Novais, A. Q. (2013). Reactive scheduling in a make-toorder flexible job shop with re-entrant process and assembly: a mathematical programming approach, International Journal of Production Research, Vol. 51, No. 17, 5120-5141, doi:10.1080/00207543.2013.793428

[18] Yang, X.-Y.; Shi, G.-H.; Wang, X.; Sun, H.-Y. (2013). Optimization for one-piece discrete production scheduling based on lean logistics, Industrial Engineering and Management, Vol. 17, No. 3, 11-18

[19] Vidal, J. C.; Mucientes, M.; Bugarín, A.; Lama, M. (2011). Machine scheduling in custom furniture industry through neuro-evolutionary hybridization, Applied Soft Computing, Vol. 11, No. 2, 1600-1613, doi:10.1016/j.asoc.2010.04.020

[20] Phanden, R. K.; Jain, A.; Verma, R. (2013). An approach for integration of process planning and scheduling, International Journal of Computer Integrated Manufacturing, Vol. 26, No. 4, 284302, doi:10.1080/0951192X.2012.684721

[21] Li, X.; Gao, L.; Zhang, C.; Shao, X. (2010). A review on integrated process planning and scheduling, International Journal of Manufacturing Research, Vol. 5, No. 2, 161-180, doi:10.1504/ijmr.2010.031630

[22] Laili, Y.; Tao, F.; Zhang, L.; Sarker, B. R. (2012). A study of optimal allocation of computing resources in cloud manufacturing systems, International Journal of Advanced Manufacturing Technology, Vol. 63, No. 5-8, 671-690, doi:10.1007/s00170-012-3939-0

[23] Cheng, Y.; Tao, F.; Liu, Y.; Zhao, D.; Zhang, L.; Xu, L. (2013). Energy-aware resource service scheduling based on utility evaluation in cloud manufacturing system, Proceedings of the 
Institution of Mechanical Engineers, Part B: Journal of Engineering Manufacture, Vol. 227, No. 12, 1901-1915, doi:10.1177/0954405413492966

[24] Korambath, P.; Wang, J.; Kumar, A.; Hochstein, L.; Schott, B.; Graybill, R.; Baldea, M.; Davis, J. (2014). Deploying Kepler workflows as services on a cloud infrastructure for smart manufacturing, Procedia Computer Science, Vol. 29, 2254-2259, doi:10.1016/ j.procs.2014.05.210

[25] Wang, X. V.; Givehchi, M.; Wang, L. (2017). Manufacturing system on the cloud: a case study on cloud-based process planning, Procedia CIRP, Vol. 63, 39-45, doi:10.1016/ j.procir.2017.03.103

[26] Xu, X.-Y.; Pan, Y.; Ling, C. (2012). Power-aware resource scheduling under cloud computing environment, Journal of Computer Applications, Vol. 32, No. 6, 1913-1915, doi:10.3724/sp.j.1087.2012.01913

[27] Evola, G.; Marletta, L.; Cimino, D. (2018). Weather data morphing to improve building energy modeling in an urban context, Mathematical Modelling of Engineering Problems, Vol. 5, No. 3, 211-216, doi:10.18280/mmep.050312

[28] Dai, Y.; Pang, L.-P.; Chen, L.-S.; Zhu, X.; Zhang, T. (2016). A new multi-body dynamic model of a deep ocean mining vehicle-pipeline-ship system and simulation of its integrated motion, Strojniski vestnik - Journal of Mechanical Engineering, Vol. 62, No. 12, 757-763, doi:10.5545/sv-jme.2015.3211 